\title{
Retired Educators' Career Transition as a New Life Role of Underwriting Career Development in Botswana
}

\author{
Hildah L. Mokgolodi ${ }^{1}$
}

Received: 1 July 2019 / Accepted: 1 September 2020 / Published online: 8 September 2020

(C) Springer Nature B.V. 2020

\begin{abstract}
Retired educators of Botswana strongly disagree with the idea that a retiree is a liability and cannot contribute to a system's advancement. The study explores retired educators' view that career development of young persons can benefit from retirees' career transitional experiences, through mentoring. In-depth interviews were conducted with 16 individuals and 3 groups of retirees. Career construction and phenomenological principles informed the study, while, thematic analysis reflected the experiences of retired educators. Four themes emerged, including, Meaningful experiences for retired educators and Recommendations for future education programmes. Interview excerpts are evidence for acquired self-awareness and leadership, soft skills, necessary for career development. Mentoring and reflective forums are some ways retired educators could be engaged in career development.
\end{abstract}

Keywords Career development · Mentoring $\cdot$ Retired educators $\cdot$ Career transition $\cdot$ Soft skills

\section{Introduction}

Exposure to skills development within one's own profession, impactful experiences such as career transitions, exceptional leadership, and mentoring, are not only but some of the practices that can form foundations for career development programmes for schools and young professionals. This article highlights the findings on the meaningful career and life experiences of retired educators, which led to the acquisition of soft skills. The implication of these findings is that soft skills can be transferred to younger generations through mentoring. The retired educators imagined transitioning to new

Hildah L. Mokgolodi

hildah.mokgolodi@mopipi.ub.bw; hlmokgolodi@gmail.com

1 University of Botswana, Gaborone, Botswana 
and meaningful life roles as mentors and more, rather than disappearing as virtually assumed for people who are labelled retired. Furthermore, although these retired educators were teachers at the beginning of their careers or remained teachers until retirement, all transitioned and diversified into positions of responsibility at different levels. These experiences were realised, through research, to be valuable for yet another transition in career development.

\section{Objective of the Study}

The study explored how career development of young people can benefit from mentoring by seasoned, retired, education career professionals. Therefore, phenomenological principles and a constructivist approach were used to explore in depth: the experiential knowledge and skills important for career development acquired through workplace learning; and how the acquired experiential knowledge and skills of retired educators could stipulate career development aspects.

\section{Theoretical Framework}

People make meaning when they share personal experiences. A new paradigm was necessary in the twenty-first century to address issues of the self and the environment with a focus on 'employability, adaptability, emotional intelligence, and lifelong learning' in models of intervention (Savickas 2011, p. 12; Zunker 2016). While the Life-Span, Life-Space approach promotes self-concept as key to career behaviour, Career Construction theory interest is in the construction of the self, using an individual's work and relationships to conceptualise such (Savickas 2011; Super 1990; Zunker 2016). In other words, careers are subjective and individuals relate who they are to what they do; hence, one would decide on what kind of life they would like to live and how to use work in living that specific life. An assumption is that retired educators will continue to identify with what they postulate to be their new role during retirement. Therefore, Career Construction theory emphasises reflective thinking of past present and anticipated roles (Savickas 2011; Maree 2013) and quite suited for retirement (Lytle et al. 2015). Retired educators could only construct new life roles to include supporting career development of upcoming professionals, as they transition from fulltime employment to other forms of work. Reflective thinking seems central to the development of career programmes.

\section{Literature Review}

The literature review to the study highlighted self-awareness, interpersonal relationships, decision-making, stress tolerance, leadership skills and other emotional intelligence skills, such as communication, as soft-skills expected to be learned through an individual's career development. Based on the literature, mentoring was identified as one way in which the above soft-skills and other skills could be cultured in learners and young professionals by retired educators. 
Mentoring can be described in terms of varied relationships where the mentor assists the mentee to navigate a certain territory (Lunsford et al. 2017; Mokgolodi 2015). Mentoring does not only bring better performance, but "Perseverance in education, Leadership skills, Cognitive and socio-emotional growth (learning, sense of belonging)" in learners at "undergraduate; Socialization, Academic support, Program/advisor satisfaction, Scholarly productivity in graduate students" while the outcomes of mentoring in lecturers include, "Career satisfaction, Promotion and retention, Job knowledge/skills "(Lunsford et al. 2017 p. 327). Given the above outcomes of mentoring, a single definition may not be reached, however, it is important to realise that there are relational, developmental and contextual issues as described in Ambrosetti and Dekkers (2010) and Ambrosetti et al. (2014). Furthermore, mentoring facilitates career and organisational development. Retired educators with their wealth of knowledge are likely to elicit development, interpersonal relationships and skills development in both learners and young professionals within their localities through mentoring. For instance, co-authoring of manuscript by new educators and retired educators; co-teaching or guiding a learner through an assignment or their learning (Mokgolodi and Gaotlhobogwe 2020) may be just the support needed for one's career expansion.

Researchers have identified roles that mentors assume in different contexts, which can assist leaners and young professionals to set goals and stick to them. These roles include supporter, role model, facilitator, assessor, collaborator, friend, teacher/trainer, protector, evaluator and communicator (Ambrosetti and Dekkers 2010; Ghosh 2012; Kamm, and ASME 2019). Mokgolodi and Gaotlhobogwe (2020) also advocated for retired educators as career resource tools, pointing out more roles they could assume in learning institutions and organisations as mentors, , teachers of interpersonal, leadership and other life skills. Further to this, psychological support and counselling are critical in a mentor and mentee relationship (Borders et al. 2011; Fifolt and Searby 2010), which experienced professionals may relate to, hence offer. Although it is common that mentoring is a face to face venture, it does not always have to be, given the current developments in information communication technologies (Owen 2015) and COVID19 which requires social distancing. Retired educators' age and COVID-19 should not limit their participation in mentoring young people post retirement. They can continue to educate through video recordings, virtual meetings etcetera. Mokgolodi and Gaotlhobogwe (2020), found from their study that involvement of retired professionals in mentoring activities post retirement has great benefits to the education system, their health, which reduces government spending on them.

\section{Method}

As a qualitative study, phenomenological approach was used to explore the meanings behind the retired educators' experiences, which can add value to career development. In addition, phenomenology was used to find out how retirees constructed and interpreted their realities in their own words (Borrero and Kruger 2015). The method outlines the acquisition of the sample, the instruments used and the procedures carried out. How the data is analysed and ethical concerns are highlighte in this section. 


\section{Sample}

The participants in this study are a sample from phase 2 of a larger study. All the participants were retired educators and Batswana (people of Botswana) who worked in and around Gaborone, Botswana. Hence, they spoke both Setswana (most-spoken local language) and English (the official language). There were 19 participants in total. Sixteen 16 ( 7 males and 9 females) participants took part in the individual interviews and there were 3 focus group discussions (FGDs) of 5, 5 and 6. A focus group was considered as a single participant. Data saturation had been reached by the 16th participant for individual interviews. FGDs brought out information from the interaction of members that may otherwise not been highlighted in individual interviews (Cohen et al. 2011). The retired educators who took part in this study had been retired for at least one year. All the participants were in leadership positions at the time of retirement and these included heads of departments, heads of colleges of education and education officers up to the permanent secretary level, being the highest public office in the Ministry of Education. The mean work experience for the retired educators was 29 years. Those who participated in the individual interview were aged between 50 and 63 years, with education levels from bachelors to $\mathrm{PhD}$. The FGD participants' age range was 45-72. Though retired from formal employment as educators, more than $50 \%$ of these participants still worked as formal employees in different organisations, while the rest always took part in community activities in order to keep active.

\section{Instruments}

The interview guide for both the semi-structured individual interview and the FGDs which were used for this article were informed from the analysis of the questionnaire in phase 1 of the larger study. The retired educators were requested to relate meanings they attached to their life experiences. In addition, participants had to highlight the skills learnt and if those skills were transferrable to new career programmes. Interview guiding questions for both the individual interviews and FGDs can be accessed from the appendices $\mathrm{G}$ and $\mathrm{H}$ of the main study at http://hdl.handle.net/2263/44142. Meaning-making as guided by Career Construction and other narrative theories (Savickas 2012, 2013; Maree 2013) was what was sought from the participants in order to answer the research purposes.

\section{Procedure}

As a result of this sample being nested in the survey, at the end of the survey questionnaire, the respondents answered whether they wished to continue with the study by taking part in a focus group discussion or an in-depth individual interview. If they responded yes to the above request, then they had to include their contact details for a follow-up. However, the criteria for participation beyond answering yes included respondents who attempted the whole questionnaire, and for the individual interviews, they should not have participated in the FGDs. Key participants were selected for individual interviews based on their intense response to the qualitative aspect of the questionnaire in the first phase of the study. Snowballing was also used to get more participants for both interviews. Only after data saturation were participants invited for 
FDGs. The interview questions were the same for both individual and FGDs. Then the retired educators who took part in the study were called to set up times for the interviews. Data collected from both FGDs and individual interviews, was audio recorded. Field and reflective notes from the researcher's observation formed part of the data that informed the study (Charmaz 2010). The in-depth individual interviews took 60 min each, whereas the FGDs ranged from 60 to 90 min.

To avoid bias, I engaged in a lot of reflexivity. As a researcher approaching early retirement, I experienced strong emotion at some participants' experiences (Creswell 2009, 2014; Mokgolodi 2015, p. 307). I was at the pick of my career, however, I could relate with frustrations from the non-recognition of the retired educators' potential to improve the education system by the Ministry of Education leadership. Since the main study was a doctoral study, my advisers audited the study and data collection process through reflective meetings.

\section{Data Analysis}

Data analysis started early on inception of the study. However, thematic analysis was used after data collection. Based on Creswell's (2013) data spiral, data from transcriptions, observations and researcher notes was organised to make it easily accessible. Data from pages of verbatim transcriptions of the retired educators' lived experiences interviews was overwhelming and needed to be reduced and condensed to make it easy to work with. The data was then interpreted into codes and themes through a systematic process, which included using colour codes (Ivankova 2014; Miles et al. 2014). The reiterative process of reflecting back on the researcher's position and biases as an educator who was approaching early retirement age and working with data from individual interviews and FGDs ensured analysis was from in-depth and rich data (Charmaz 2005, 2010; Cohen et al. 2007, 2011). The final stage involved representing data visually and making conclusions.

\section{Trustworthiness}

The participants in the study had the opportunity to check and read the transcriptions to verify that what they said regarding their experiences was true and was what they meant to say. The findings from FGDs and literature corroborated the findings from the indepth individual interviews also .

\section{Results}

Four themes emerged from the study. These were meaningful experiences for retired educators; retired educators experiencing inspirational leaders; recommendations for future education programmes; and retired educators' issues for retirement.

\section{Theme 1: Meaningful Experiences for Retired Educators}

Theme 1 had two sub-themes, which were Transitions and turning points and Exposure for skills development. 
The participants highlighted that meaning and impact of experiences came from feedback from mentoring, being given autonomy, experiencing values such as caring in different cultures and being valued. In the process, these, brought about the development of necessary soft skills and knowledge such as self-discovery. A participant said,

"I was 24 years. I was promoted to a position of a deputy school head...my experience...taught me that as a young man I have to change the way I was thinking." (FGD 3: 11-14)

Another participant, on the other hand, argued,

"It all came from those two experiences: one, the culture which I found there, a culture of great caring and passion for your work and passion for the children. The other influence, the key one, that statement that ... made about working as a team. See, and so those two things guided me all my working life." (Ind 8:161165)

The reflections on the above experiences by retirees imply that self-awareness, learning what was expected, such as working in a team and learning of one's capabilities were important in their career development. These were results of mentoring in different cultures and through positions of responsibility.

Furthermore, another participant had this to say,

"Professional development is critical in the life of a professional, no matter at what level you are trained. You need to continuously refuel ... conferences, ... benchmarking were critical to this experience and I found that to be very useful in the life of an educator. Yes, looking back I realise that it played a critical role in helping me become successful in the services that I provided to the teachers." (Ind 2:70-82)

Conferences and benchmarking are highlighted here as methodological ways which can be used for mentoring young professionals into effectively performing their duties. Experiences of the retired educators are likely to transfer into their mentees.

\section{Theme 2: Retired Educators Experiencing Inspirational Leaders}

Laying the foundations for mentoring was the only sub-theme in theme 2 . The experiences that the participants in the study could remember were those from leaders who were inspirational in the field of education. The leaders were passionate about education, dedicated, knowledgeable, were visionaries, team players and commanded respect. Therefore, the retired educators' leaders played the role of mentors.

The following excerpts highlight some issues relating to inspirational leadership and mentoring:

"So, I was totally lost and shocked and scared and all the negatives. I knew absolutely nothing ...He said one profound thing and that's what guided me throughout my whole career." (Ind 8: 71-78) 
Another individual said

"During those days, the school head was a jack of all trades, a parent, a role model, a community leader and so on, and I must say, I am quite pleased that the gentleman is very much around. He is so old, but he is still there in the village, and those foundations he laid are still in me." (Ind 16: 386-390)

Additionally,

"Ma G became a serious role model for me and pushed me into becoming a teacher for children with intellectual disabilities and later on with learning disabilities, because of how she carried herself. She wouldn't look at herself just as a teacher in the classroom. She would be a housemother where I was a dormitory mother myself and I was under her and later on she gave me that role of being a housemother." (Ind 15:793-800)

The roles played by mentors are not limited to acting as parents, role models and teachers. Participants are clear in that mentors needed to lead by example in order for mentees to emulate expected behaviour as a professionals.

\section{Theme 3: Recommendations for Future Education Programmes}

The theme was defined as ways in which knowledge and skills acquired by retired educators can be made practically available to career development programmes. These career development programmes were not isolated to schools but to growing professionals as well. Two sub-themes emerged as Areas of expertise and Ways of utilising the knowledge and skills of retired educators. Excerpts included:

"I'm saying let's develop a mentoring training programme and... let's agree what this person is going to do in this school and train them and develop a system for structuring the way they will contribute and the way you will monitor this contribution." (Ind 12: 451-457)

The above extract highlights that mentoring has to be relevant for its purposes. It is worth noting that the retiree here was aware that their engagement should be measurable and monitored. Another retired educator said

"A retired educator can be helpful to an upcoming professional through forming maybe some kind of associations .. when we are together as professionals, we can come up with programmes that can benefit these young people." (Ind 10:255259)

The quote above highlights the need for reflective meetings that could benefit young people. Yet another had this to say,

"Get that database and say what could be called watershed moments. If these are the major landmarks in the history of the development of education, we can then 
link these landmarks with the database and find out from the databases who were the key actors, who were involved in the development of education training in Botswana. As I said, we are not talking about a few officers or permanent secretaries, but a whole lot of teachers and school heads, and I think most of those will have a story to tell." (Ind 16:483-489)

The above except emphasised the value in keeping databases for exceptional events, key players and key results that can be referenced in the future post retirement of innovators and actors. With the number of teachers passing through the education system, including retired educators, so would the events which could be recorded. Another participant, however, pointed out that,

"There seems to be an attitude in the Ministry [of Education] at the moment that nothing happened before the present, batho ba ba leng teng (people currently in place). Nothing happened before we came here, so everything is starting afresh." (Ind 8:832-835)

The statement of the participant seemed to suggest that current educators assume there was no baseline in education activities. If they did not, the educators now could engage with retired educators. Thisparticipant emphasised,

"I don't think we've got a lot of resources to waste and a number of people out there can really contribute ideas and I think we need .. a very structured way of engaging with these different stakeholders for different things... I think when they are engaged in a meaningful way, they can contribute a lot." (Ind 12:414-418, 424-428)

The point was that retired educators are a valuable resource. The participant pointed out that if retirees' engagement is organised, much can be harnessed from their being.

The participants stipulate how they could influence career development programmes through mentoring. From the study, the retired educators seemed to suggest that they would prefer to make their contribution in in-service training of young professionals and in policy reforms. Retired educators highlighted their expert knowledge and skills such as policy development and leadership. Furthermore, the retired educators specified how they thought their knowledge could impact career growth programmes. Examples detailed included the use of databases, reflective forums, training and mentoring (Mokgolodi 2015).

\section{Theme 4: Retired Educators' Retirement Issues}

This theme was defined as factors that relate to retirement and the termination of services as an educator. Retired educators' experiences that led them to retire and their reflections on their retirement at the time of the interview in this study are included. Factors that affected retirement and post-retirement activities of retired educators were sub-themes.

Retired educators retired for different reasons. These included mainly challenges they had with leadership or when the retired officer at the time of work felt they were 
no longer able to make a difference. These issues were directed by how the retired educator felt at the time of the interview as they reflected on their experiences; hence, one participant claimed that,

"There's a lot of rigidity in our education system and rigidity sometimes thwarts creativity and innovation, yes, the red tape ... what pained me and probably even made me leave the MoESD (Ministry of Education and Skilled Development) was the failure to implement policy and the failure to take professional expert advice. When people have put you in a place and you have the technical knowhow and the professional know-how, they need to get guidance from you." (Ind $7: 425-433)$

The above except reveals how lack of creativity and innovation as a result of lack of applying one's knowledge and skills can lead to dissatisfaction and frustration, hence early retirement. More importantly, the retiree is skilled, technically and professionally, enough to give mentorship to both young professionals and leadership. The aforementioned excerpt for this last theme is indicative of an employee who retired not because of age, but mainly because they were frustrated with the system they worked for. They could no longer use their skills and knowledge to support the education structures. Therefore, retirees saw the education system as not being progressive to stay in. The study highlighted that some participants retired because the educational environment was not conducive for one to continue as an educator, which is consistent with Larschan's (2016) argument that his retirement was also effected by administrators concerned with the bottom line rather than standards.

In the post-retirement sub-theme, the researcher discussed retired educators' current occupations post-retirement. It seemed retired educators were engaged in varied activities, some related to their occupation prior to retirement, while others were engaged in different work roles. For instance, a retiree continuing with what they did prior to retirement highlighted,

"I' $m$ in counselling. I'm a marriage and family therapist and I'm enjoying my job in that I work at my own pace as a retired person. The adjustment wasn't very severe. I may not have enough in terms of resources, but I feel fulfilled in that I had reduced the severity of leaving formal employment by preparing beforehand." (Ind 9:515-519)

But a retiree whose experience led them to change said,

"I had already said I don't want to do anything in special education. I want to do something completely different and I went into the .... I was a ... chairperson." (Ind 15:869-872)

The implication is that retirement can be pleasant or severe, depending on one's experience during their career and the level of preparedness towards it. The preparation could be psychological, financial and in terms of activities the retiree has in place for continuation after retirement. Engaging in a similar line of work, working at own pace 
implied a happy and more relaxed retiree. Both retirees on the above two quotes can use their experiences as mentors of young professionals.

Other retired educators are engaged as teachers on contract in schools (FGD 1, 2, $3)$.

"I was at a certain school for three months last year; I volunteered there." (FGD $3: 822-823)$

This engagement post retirement is an example of how retired educators can continue to mentor young people.

The qualitative aspect of the survey questionnaire (Question 22f), from the first phase, indicated that only $21 \%$ of the retired educators are involved in education-related activities. On the other hand, the majority (64\%) of them were involved in farming, community work and homemaking (Mokgolodi 2015). The retired educators engage themselves in different ways post retirement, as mentors as volunteers, contract employees and farmers. The data indicated that retired educators spent minimal time in education-related activities, where their acquired skills would be more valuable according to them. This was not surprising, given what the participants alluded to the Ministry of Education ignoring them. Additionally, the literature contends that retirement has effects such as withdrawal from society because of the perceptions that the retirees have about what others think of them (Owton 2011).

\section{Discussion}

This study was set out to determine how, through their new life role, retired educators could transition to mentoring young people's career development. Key to this objective was determining critical soft skills necessary for career development, that could be mentored, based on retired educators' experiences. The significance of this study is consistent with Browning et al.'s (2017) emphasis that a great deal can be learnt from the experiences of those who have successfully navigated the transitions.

It was found out that exposure to mentoring of retired educators by inspirational leaders led to self-discovery or self-awareness, interpersonal, decision-making and leadership skills in addition to professional knowledge as an educator. Self-awareness was important in developing knowledge and soft skills necessary for career growth. How self-discovery develops soft skills is a field for research. Relating career construction, career adaptability and career interventions as highlighted in Maree (2019) seems to slightly explain why. Career programmes should inspire self-discovery, passion of being a student or a young professional and a culture of teamwork through continual injection of new developments and interventions. The researcher in this study hypothesises that learning how to work in a team is an antecedent to developing interpersonal skills, which may be very critical for the changing nature of careers. Young professionals may find negotiating the world of work easier with both interpersonal skills and self-awareness. Career development theories, such as Holland's typology, highlight self-concept as necessary to choose careers that are in line with one's personality, values and interests (Zunker 2016). If central to career development is selfawareness, it can probably be argued that continual exposure to novel situations 
enhanced meaning-making of the self, hence fresh skills development of retired educators.

The findings in this study seemed to suggest that passion and excitement by mentors and leaders could enhance the same in mentees or supervisees. A study by DeCesare et al. (2017) highlight the impacts retired mentors had on new teachers. DeCesare et al. (2017) concluded that there is a return on investment and significant benefits for schools using retired mentors with regard to reading and maths compared to schools which did their job as usual. Therefore, mentorship, as part of career programmes, cannot be overemphasised. As young professionals, retired educators in this study had leaders that led by example and exercised their roles more as mentors rather than just as leaders. Mentors should allow for creativity and innovation in practice; therefore, social networks of retired educators acting as mentors could be a career resource for all career aspirants (Hunter et al. 2018).

Highlighted in this study is leadership cum mentorship as an activity one acquires and that an individual should pursue out of interest rather than as a position of responsibility. In addition to leadership skills, it was found that over the years, the retired educators also acquired skills in in-service training, policy reform and many more which could be strategies for mentorship (Mokgolodi et al. 2017).

The retirees suggested that structured mentorship programmes, reflective meetings and engaging retirees in meaningful ways can go a long way in developing learners and young people's careers. As highlighted in the literature above, retired educators' mentorship will bring about job or learning satisfaction as their mentees experience both cognitive and socio-emotional growth. Databases of expert skills of retired expert educators and their landmark developments and best practices can be needed resource reference for further education career programmes. Flexibility in engaging retired educators such as using available technologies could assist young professionals interpret policies and education Acts (Government of Botswana 1967) that they developed or implemented and are still in use. It cannot be assumed that the succession planning in education systems is full proof such that these Acts and policies can be well understood by professionals coming in three to five decades later. The other contention is that millage and growth of education schemes can result in continuity rather than start-ups by newly employed educators. Therefore, reflective forums for retired educators with anybody in education could serve as benchmarking platforms for or help develop the professional identity of young professionals.

Furthermore, based on the results, the retired educators in the study were undergoing yet another critical life transition in their career lives, which Allison, Thomas and Larschan (2016) refer to as the next phase. The life transitions the retired educators seemed to be experiencing is justified by the abortion of compulsory retirement age (Allison et al. 2016; Lake et al. 2016; Wei and Jiaoyu 2017.). This means retirement is really a personal entity based on a number of factors, hence should not be forced on people because of one's age. The personal journey, full of emotion, expectations of oneself and intellectual pursuit as observed by Owton (2011) seems to be of little consequence to Botswana's education system other than it is the end of paid employment. This transition is not looked at as a productive transition but a slowing down changeover by the rest of society in Botswana, including workplaces that know an individual has only retired. Bergman (2018) underscores the unconsciously internalised negative attitude towards older adults in many cultures. 
Retirement is therefore conceptualised differently by different people including researchers and retirees themselves. Retirement can be a decision-making issue, an adjustment process, a career development stage or a part of a human resource management strategy (Wang and Shultz 2010; Wang and Shi 2014). For these educators, retirement in their cases could not be defined in the classical terms of retirement but job and role transition. The retirees only moved from their first jobs as educators to other forms of employment, where they could apply similar skills to the ones they already have, as some retired early (Lake et al. 2016). In the changing world of careers, it can be argued that retirement may not necessarily exist in its pure form, but as a government tool to renew itself and rid itself of aged professionals. The meaning that these retired educators developed of themselves is observed from what they consider ways that they could enhance the development of career programmes. Therefore, retirement age is but only a number that governments use to allow for injection of new energy into any professional system. Most participants in this study claimed they had it in them to assist upcoming professionals and young learners, yet the government was denying them that opportunity.

\section{Implications for Career Practice and Further Research}

Practice: Retired educators are a resource that educators and career counsellors should consider amongst the tools they use in their work. The implication here is that retired educators would not only serve as facilitators or mentors in career decision-making processes, study skills, leadership, research or mathematics, but as needed role models for young people desperate for individuals to look up to (DeCesare et al. 2017; Browning et al. 2017; Mokgolodi and Gaotlhobogwe 2020). Role models are critical to instilling important cultural values in young people in a world full of competing challenges and demands for them (Msimanga et al. 2018). Botswana may seem to be developed and too westernised, as a middle-income country; however, career counselling seems to still be foreign to Batswana. Using retired educators as part of indigenisation of career counselling approaches may develop the right soft skills for career growth. It is worth highlighting that education is viewed by both actively employed and retired educators as a noble profession and not to be pursued by those intending to be rich (Retirement Market Insights 2017).

Secondly, from an early age, or early on in one's profession, individuals can be prepared for the changing world of careers so as to prepare for life rather than working towards retirement age. Critically, young people need not be self-aware, leaders, or relate well with others only at the height of their careers but can start working on these at the initial years of their lives. Career construction interview encourages the use of role models in career decision-making and/or choosing careers. Retired educators may serve this part in real time in intergenerational learning, videos, or any media applicable to the situation.

Future research: A considerable number of researches have been conducted on the effects of retirement on older workers and theories of career development. However, it seems more research is needed on positive ways to engage retired educators and other professionals in innovative and creative career development programmes for learners and upcoming specialists. 


\section{Summary}

The study set out to argue for the engagement of retired educators in career development of young people. While direct teaching and training can be applied by retired educators, from the study, structured mentoring comes through very strongly as a strategy that the country can use to develop soft-skills such as decision-making, interpersonal, leadership, cognitive and socio-emotional ones in the development of careers.

\section{Limitation of the Study}

The study could not find from the young people themselves how they thought retired educators could improve their career development.

\section{References}

Allison, L., Thomas, E., \& Larschan, R. (2016). What does retirement mean for academics? Getty/iStock montage.

Ambrosetti, A., \& Dekkers, J. (2010). The interconnectedness of the roles of mentors and mentees in Preservice teacher education mentoring relationships. Australian Journal of Teacher Education, 35(6), 42-55. https://doi.org/10.14221/ajte.2010v35n6.3.

Ambrosetti, A., Knight, B. A., \& Dekkers, J. (2014). Maximizing the potential of mentoring: A framework for pre-service teacher education. Mentoring \& Tutoring: Partnership in Learning, 22(3), 224-239. https://doi.org/10.1080/13611267.2014.926662.

Bergman, E. J. (2018). Aligning career aspirations with demographic reality: The role of gerontology and geriatric educators in shaping student attitudes and behaviour. Gerontology \& Geriatrics Education, 39(3), 265-267.

Borders, L. D., Young, S., Wester, K. L., Murray, C. E., Villalba, J. A., Lewis, T. F., \& Mobley, A. K. (2011). Mentoring promotion/tenure-seeking faculty: Principles of good practice within a counselor education program. Counselor Education \& Supervision, 50(March 2011), 171-188.

Borrero, L., \& Kruger, T. M. (2015). The nature and meaning of identity in retired professional women. Journal of Women \& Aging, 27(4), 309-329. https://doi.org/10.1080/08952841.2014.950141.

Browning, L., Thompson, K., \& Dawson, D. (2017). From early career researcher to research leaders: Survival of the fittest. Journal of Higher Education Policy and Management, 39(4), 361-377. https://doi. org/10.1080/1360080x.2017.1330814.

Charmaz, K. (2005). Grounded theory in the 21st century: Application for advancing social justice studies. In N. K. Denzin \& Y. S. Lincoln (Eds.), The sage handbook of qualitative research (3rd ed.). Thousand Oaks: Sage.

Charmaz, K. (2010). Grounded theory: Objectivist and constructivist methods. In W. Luttrell (Ed.), Qualitative educational research: Readings in reflexive methodology and transformative practice. New York: Routledge.

Cohen, L., Manion, L., \& Morrison, K. (2007). Research methods in education (6th ed.). London: Routledge.

Cohen, L., Manion, L., \& Morrison, K. (2011). Research methods in education (7th ed.). London: Routledge.

Creswell, J. W. (2009). Research design: Qualitative, quantitative, and mixed methods approaches (3rd ed.). Thousand Oaks: Sage.

Creswell, J. W. (2013). Qualitative inquiry and research design: Choosing among five approaches (3rd ed.). Los Angeles: Sage.

Creswell, J. W. (2014). Research design: Qualitative, quantitative and mixed methods approaches (4th ed.). Los Angeles: Sage.

DeCesare, D., McClelland, A., \& Randel, B. (2017). Making an impact: Impacts of the retired mentors for new teachers program. IES National Center for Educational Evaluation and Regional Assistance. U.S. Department of Education. 
Fifolt, M., \& Searby, L. (2010). Mentoring in cooperative education and internships: Preparing Protégés for STEM professions. Journal of STEM Education, 11(1 \& 2), 17-26.

Ghosh, R. (2012). Mentors providing challenge and support: Integrating concepts from teacher mentoring in education and organizational mentoring in business. Human Resource Development Review, 12(2), 144 176.

Government of Botswana (1967). CHAPTER 58:01 EDUCATION.

Hunter, K., Wilson, A., \& McArthur, K. (2018). The role of intergenerational relationships in challenging educational inequality. Improving participation of working-class pupils in higher education. Journal of Intergenerational Relationships, 16(1-2), 5-25.

Ivankova, N. V. (2014). Implementing quality criteria in designing and conducting a sequential QUAN $\rightarrow$ QUAL mixed methods study of student engagement with learning applied research methods online. Journal of Mixed Methods Research, 8(1), 25-51. https://doi.org/10.1177/1558689813487945.

Kamm, R. D. \& ASME (2019). Mentoring and education: a lifetime of experience and learning. Journal of Biomechanical Engineering, 141 (December 2019) 120301-1- 120301-5.

Lake, D. M., Allen, P. E., \& Armstrong, M. L. (2016). Capitalising on military nurse skills for second career leadership and staff development roles. The Journal of Continuing Education in Nursing, 47(11), 503510.

Larschan, R. (2016). Now in my Manhattan pied-a'-terre, I decided to focus on activities that would make at least some use of my academic training - but without constraints of full-time employment. Getty/Alamy montage.

Lunsford, L. G., Crisp, G., Dolan, E. L. \& Wuetherick, B. (2017). Mentoring in higher education. In D. A. ClutterbuckF. K. Kochan \& L. Lunsford (Ed), in: The SAGE Handbook of Mentoring. DOI: https://doi. org/10.4135/9781526402011.n20 p. 316-344.

Lytle, C., Foley, P. F., \& Cotter, E. W. (2015). Career and retirement theories. Relevance for older workers across cultures. Journal of Career Development, 42(3), 185-198.

Maree, J. (2013). Counselling for career construction. Connecting life themes to construct life portraits: Turning pain into hope. Rotterdam: Sense.

Maree, J. G. (2019). Group career construction counseling: A mixed method intervention study d5s8ulwith high school students. The Career Development Quarterly, 67(1), 47-61.

Miles, M. B., Huberman, A. M., \& Saldaña, J. (2014). Qualitative data analysis: A methods sourcebook. Los Angeles: Sage.

Mokgolodi, H.L. (2015). Harnessing experiential knowledge and skills of retired educators to inform career development programmes in Botswana, $\mathrm{PhD}$ Thesis, University of Pretoria, Pretoria, viewed yymmdd http://hdl.handle.net/2263/44142

Mokgolodi, H. L., \& Gaotlhobogwe, M. (2020). Retired professionals as a career resource tool for schools in Botswana: Effective partnerships in education. Mosenodi-International Journal of Educational Studies, 23(1), 2020.

Mokgolodi, H. L., Mohangi, K., Lubbe-Debeer, C., Scheman, V., \& Sefotho, M. M. (2017). Capturing the knowledge and skills of retired educators for supporting the career development programmes of a young workforce: An exploratory study from Botswana. Indian Journal of Career and Livelihood Planning, 5(1), 26-35.

Msimanga, S. H., Mokgolodi, H. L., \& Chihambakwe, W. (2018). An exploration of the culture of Ubuntu and its impact during supervision of students pursuing higher education. Scholars Journal of Arts, Humanities and Social Sciences, 6(6), 1293-1298. https://doi.org/10.21276/sjahss.2018.6.6.17.

Owen, H. D. (2015). Making the most of mobility: virtual mentoring and education practitioner professional development. Research in Learning Technology 23 (2015) 25566, https://doi.org/10.3402/rlt.v23.25566.

Owton, H. (2011). Retired lives. International Journal of Lifelong Education, 30(2), 275-278. Doi: 1080/02601370.2011.555618.

Retirement Market Insights. (2017). Retiring after a career as an educator. Retirement Market Insights, 13(5), $15-17$.

Savickas, M. L. (2011). Career Counselling. In J. Carlson \& M. Englar-Carlson (Eds.), Theories of psychotherapy series. American Counselling Association: Washington.

Savickas, M. L. (2012). Life design: A paradigm for career intervention in the 21st century. Journal of Counseling and Development, 90(January 2012), 13-19.

Savickas, M. L. (2013). Career construction theory and practice. In R. W. Lent \& S. D. Brown (Eds.), Career development and counseling: Putting theory and research to work (2nd ed., pp. 147-183). Hoboken: Wiley. 
Super, D. E. (1990). A life-span, life-space approach to career development. In D. Brown, L. Brooks, \& Associates (Eds.), Career choice and development: Applying contemporary theories to practice (2nd ed., pp. 197-261). San Francisco: Jossey-Bass.

Wang, M., \& Shi, J. (2014). Psychological research on retirement. The Annual Review of Psychology, 65, 209-233. https://doi.org/10.1146/annurev-psych-010213-115131.

Wang, M., \& Shultz, K. S. (2010). Employee retirement. A review and recommendations for future investigation. Journal of Management, 36(1), 172-206. https://doi.org/10.1177/0149206309347957.

Wei, H. C., \& Jiaoyu, Y. Y. (2017). Preparation of active aging life for educators. A beginning of later-life learning experience. Journal of Education Research, 283(2017), 28-40. https://doi.org/10.3966 /168063602017110283003.

Zunker, V. G. (2016). Career counseling, a holistic approach (9th ed.). Australia: Cengage Learning.

Publisher's Note Springer Nature remains neutral with regard to jurisdictional claims in published maps and institutional affiliations. 